\title{
Study on Pregnancy Outcomes in Intrauterine Insemination Cycles with Motile Spermatozoa Insemination
}

\author{
Mafruha Khanam ${ }^{1 *}$ \\ Rokeya Begum ${ }^{2}$ \\ Aditi Banerjee $^{1}$ \\ Jesmin Jerin ${ }^{3}$ \\ Mohamed Mazih Fazyl ${ }^{4}$ \\ Shan Saadat ${ }^{5}$
}

'Department of Obstetrics \& Gynecology Institute of Applied Health Sciences (IAHS) Chattogram, Bangladesh.

${ }^{2}$ Professor of Gynecology \& Obstetrics (Retired) Chittagong Medical College

Chattogram, Bangladesh.

${ }^{3}$ Department of Obstetrics \& Gynecology Ibrahim Medical College and BIRDEM General Hospital Dhaka, Bangladesh.

${ }^{4}$ Department of Medicine

Hulhumale Hospital

Male, Maldives.

${ }^{5}$ Department of General Medicine Sher-I-Kashmir Institute of Medical Sciences Srinagar, J \& K, India.

\author{
Correspondence to: \\ Dr. Mafruha Khanam \\ Associate Professor \\ Department of Obstetrics \& Gynecology \\ Institute of Applied Health Sciences (IAHS) \\ Chattogram, Bangladesh. \\ Mobile : +8801819320386 \\ Email :drporag@yahoo.com
}

$\begin{array}{lll}\text { Date of Submission } & : & 07.08 .2020 \\ \text { Date of Acceptance } & : & 26.08 .2020\end{array}$

www.banglajol.info/index.php/CMOSHMCJ

\begin{abstract}
Background: Intrauterine Insemination (IUI) is one of the most common assisted reproductive technology methods in the world to treat various forms of infertility. The influence of number of IUI applied with the percentage of motile spermatozoa during insemination is critical on the likelihood of a successful pregnancy. The aim of our study is to assess the results of IUI as a function of the number of IUI applied with motile spermatozoa inseminated during intrauterine insemination in couples with infertility.
\end{abstract}

Materials and methods: This is a prospective study conducted in Surgiscope Fertility Centre, Chattogram, Bangladesh over 21 months on 596 couples who underwent IUI from 01/12/2017 to 30/09/2019. We performed semen analysis of the male partner from the couples who underwent IUI, calculated the sperm motility and the relationship between number of IUI applied with motile spermatozoa and the pregnancy rate of IUI. Multiple variables were selected such as, patient parameters like age of female, number of IUI, percentage of motile spermatozoa inseminated, endometrial thickness and ovulation induction protocol which were recorded and statistically analyzed.

Results: Among the 596 patients, the overall success rate was 11\%. The maximum number of successes were observed in patients with 3 IUI applications whereas the success rate was lower in comparison with decreasing IUI applications. The regression between the success and number of insemination and age indicate that there is a statistically significant positive relationship between number of inseminations completed and the rate of successful pregnancy, but no significant relationship between the number of prewash sperm and successful pregnancy. These could be due to lower population size. As an ovulation inducing agent, a $12.42 \%$ success rate was observed among the patients administered with FSH whereas $9.28 \%$ was observed for patients administered with GONAL $F$. The mean endometrial thickness was observed to be $8.914 \mathrm{~mm}$ with a minimum thickness of $4.5 \mathrm{~mm}$ and a maximum thickness of $19 \mathrm{~mm}$.

Conclusion: The rationale for the use of insemination is to increase gamete density at the site of fertilization. This revealed that intrauterine insemination should be a firstchoice treatment rather than more invasive and expensive techniques of assisted reproduction in cases of cervical, unexplained and moderate male factor subfertility.

Key words : Sperm Motility; Infertility; Insemination; Semen analysis.

\section{INTRODUCTION}

It is a simple and noninvasive technique which can be performed without expensive infrastructure with a reasonable cumulative live birth rate within three or four cycles $^{1}$. Intrauterine Insemination (IUI) is being widely used as one of the first line treatment option for infertile couples and it is a method of Assisted Reproductive Technology (ART) recognized to be successful and inexpensive $e^{2,3,4}$. 
IUI involves increasing the gamete density by inserting a high number of washed spermatozoa directly into the uterus at the time of ovulation to increase the chance of a pregnancy ${ }^{5}$.

Many factors have been considered for their potential role as both predictors and optimizers of the success of IUI including endometrial thickness, stimulation protocol, timing and number of IUI, and various seminal parameters like :-

i) Percentage of sperm with normal morphology using strict criteria

ii) Type and percentage of sperm motility

iii) Total number of motile sperms inseminated ${ }^{6,7}$. Female age is known to be an independent predictor of IUI success ${ }^{8}$.

The purpose of this study is to analyze the correlation between the number of IUI applied with motile spermatozoa insemination and pregnancy outcome in a population of 596 couples.

\section{MATERIALS AND METHODS}

This prospective study was performed on 596 couples \& conducted at the Surgiscope Fertility Centre, Chattogram, Bangladesh for 21 months from 01/12/2017 to 30/09/2019.

Female patients had tubal patency confirmed by hysterosalpingogram and men had a semen analysis. Serological tests [Syphilis, HIV, Hepatitis B Virus (HBV) HCV] were conducted for both members of the couple. Additional testing depended on any abnormalities observed. Inclusion criteria was that all these couples were unable to conceive for at least one-year, unexplained infertility, PCOS (Poly Cystic Ovary Syndrom) mild endometriosis, male factor like oligospermia, asthenoozospermia, OAT (Oligo-Astheno-Teratoozospermia) impotence, husband abroad. Couples with severe endometriosis, hypospadias, retrograde ejaculation, bilateral tubal block were excluded from the study. The primary outcome was clinical pregnancy, defined by a gestational sac and fetal heartbeat on ultrasound.

The consent of the couples was obtained faithfully in the form of informed written format after explaining how their data would be used for this study.

Ethical clearance was obtained from the relevant authority.

\section{Ovulation Induction Protocol and Monitoring}

The protocol for ovulation induction started with the first line drug, Clomiphene citrate (50-100mg 1HS x 5 days, Day 3 to Day 7). If the patient had already undergone ovulation induction with Clomiphene citrate for a maximum of 6 cycles or if the patient failed to achieve ovulation, then ovulation induction was performed with gonadotrophins, either HMG (Human Menopausal Gonadotrophin) in non-PCO (Poly Cystic Ovary) patients or FSH (Follical Stimulating Hormone) in PCO patients. A maximum of 4 cycles of IUI were performed and for couples who were unable to progress to the next line of management after 4 cycles due to financial constraints or personal reasons, a maximum of 6 cycles of IUI were done.
In cycles stimulated with gonadotrophins, Inj. Gonal F 75 IU or Inj. FSH 50 IU or 75 IU was administered on a daily basis from day 3 to day 7 . On day 8 of stimulation, assessment of follicular development was performed using transvaginal ultrasound. Once a follicle of $>17 \mathrm{~mm}$ size was identified, inj. Human Chorionic Gonadotrophin $5000 \mathrm{IU}$ (hCG) was given as an ovulation trigger and a single IUI 36 hours later or a double ovulation trigger and a single IUI 36 hours later or a double IUI, 10-12 hours prior to ovulation and 8-10 hours after ovulation was planned. Single IUI was done for selected group of patients with moderate oligoasthenospermia (510 million sperms $/ \mathrm{ml}$ ) who had financial constraints and insisted on underwent IUI for a few cycles. If four or more mature follicles $(>17 \mathrm{~mm})$ developed, the cycle was cancelled.

\section{Semen Preparation}

Semen was collected in the laboratory after 3-5 days of sexual abstinence by masturbation into a sterile plastic specimen container in the clinic. Samples were processed within 15 min of arrival (No more than $60 \mathrm{~min}$ from the time of ejaculation). Semen was transferred into a $15 \mathrm{ml}$ sterile tube containing a gradient consisting of $2 \mathrm{ml} \mathrm{45 \%}$ and $2 \mathrm{ml} \mathrm{80 \%} \mathrm{salinized} \mathrm{silica}$ (Gynotech, Malden, Netherlands) and centrifuged for $30 \mathrm{~min}$ at $400 \mathrm{~g}$. Following a 6-min centrifugation at $300 \mathrm{~g}$, the supernatant was removed, and the pellet was resuspended in $0.4 \mathrm{ml}$ of Sperm Wash Medium.

On the day of IUI, the husband was instructed to give semen that was prepared by the swim up technique or double-density gradient method with Nutrient Mixture F10 Ham. All women were provided luteal phase support with dydrorgesterone for 12 weeks. If menstrual cycle was delayed, urine pregnancy test was carried out. When positive, a transvaginal ultrasound was performed 2 weeks later to confirm a clinical pregnancy.

\section{Insemination Procedure}

One insemination was performed approximately 36 hours to 42 hours after administration of the ovulation triggering medication, employing a single use intra-uterine insemination cannula with shape memory (Laboratoire CCD, product code $12040 \mathrm{MF}$ ) to allow angulation as required for intrauterine insemination. Women were instructed to take the ovulation triggering medication at 10:00 pm and the IUI was performed after 36 hours.

An Ordinary Least Squared (OLS) regression model was used in the statistical analysis. A p-value of $<0.05$ was considered to be significant. Data was entered in SPSS version 17.

\section{RESULTS}

Data was analyzed using appropriate statistical techniques and the results were presented with tables and graphs where applicable. 


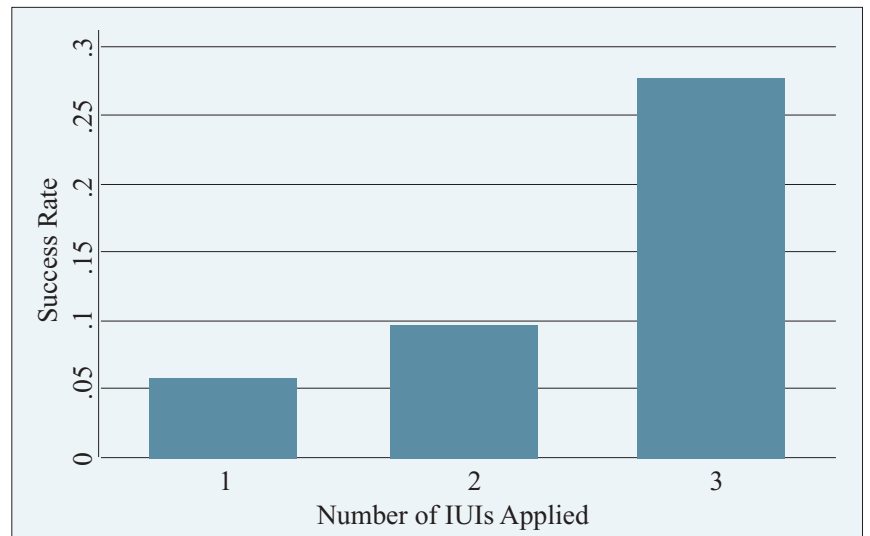

Figure 1: Success rate with number of IUIs applied.

Figure 1 shows that the maximum number of successes were observed in patients with 3 IUI applications whereas the success rate was lower in comparison with decreasing IUI applications.

Among the 596 patients, a mean of $0.119( \pm 0.032)$ were successful conceptions which is an overall success rate of $11 \%$.

Table I: Regression between success and quantity of motile sperm post and prewash.

\begin{tabular}{lr} 
Constant & \multicolumn{1}{c}{$\mathbf{A}$} \\
Q Postwash & .086943 \\
Q Prewash & .0005507 \\
R Squared & .0003478 \\
No. of Obs & 0.0031 \\
\hline
\end{tabular}

Table I shows the regression between the success and quantity of motile sperm post and prewash which indicate that there is no statistically significant relationship between number of motile sperm after wash and successful pregnancy. There is also no significant relationship between the number of prewash sperm and successful pregnancy. These could be due to lower population size.

Among the 596 patients, the mean endometrial thickness was observed to be $8.914( \pm 2.422) \mathrm{mm}$ with a minimum thickness of $4.5 \mathrm{~mm}$ and a maximum thickness of $19 \mathrm{~mm}$.

Table II: Success rate of ovulation inducing agents.

\begin{tabular}{|c|c|c|c|}
\hline $\begin{array}{l}\text { Ovulation } \\
\text { inducing } \\
\text { agent }\end{array}$ & $\begin{array}{r}\operatorname{cess} 2 \\
0\end{array}$ & 1 & Total \\
\hline \multirow[t]{2}{*}{ INJ. FSH } & 437 & 62 & 499 \\
\hline & 87.58 & 12.42 & 100.00 \\
\hline \multirow[t]{2}{*}{ INJ. GONAL L } & 88 & 9 & 97 \\
\hline & 90.72 & 9.28 & 100.00 \\
\hline \multirow[t]{2}{*}{ Total } & 525 & 71 & 596 \\
\hline & 88.09 & 11.91 & 100.00 \\
\hline
\end{tabular}

Table II shows that among the 596 patients, as an ovulation inducing agent, 499 patients were administered with FSH and 97 patients were administered with GONAL F. A $12.42 \%$ success rate was observed among the patients administered with $\mathrm{FSH}$ whereas $9.28 \%$ was observed for patients administered with GONAL F.

\section{DISCUSSION}

The maximum number of successes were observed in patients with 3 IUI applications whereas the success rate was lower in comparison with decreasing IUI applications. In accordance with our study, another study also demonstrated that patients need to underwent a few cycles of IUI to be successfully pregnant. However, more than 4 cycle of IUI will not significantly increase the clinical pregnancy rate ${ }^{9}$.

Among the 596 patients, the success rate was $11 \%$ for successful conceptions. Majority of the successful conceptions after IUI were patients below the age of 30 whereas the patients above 30 years had a significantly low $(2.7 \%)$ success rate. A similar study showed that the pregnancy rate was highest in the younger age group who were below 30 years, $6 / 18$ (33.3\%) and 30-34 years, 19/83 (22.9\%) compared with women 35-39 years, $12 / 90(13.3 \%)$ and $\geq 40$ years, $2 / 26(7.7 \%)^{10}$. Both the pregnancy rate per patient and the pregnancy rate per cycle showed a decline after the age of 39 years, however, a significant difference was found only when comparing pregnancy rates per cycle ${ }^{11}$. Our results were consistent with other previous studies that the successful pregnancy with IUI was lower in the more advanced female age ${ }^{12}$. There was evidence to support these results that oocyte quality and endometrial receptivity declined with age $\mathrm{e}^{13,14}$

In our study, the regression between the success and quantity of motile sperm post and prewash indicate that there is no statistically significant relationship between number of motile sperm after wash and successful pregnancy. There is also no significant relationship between the number of prewash sperm and successful pregnancy. These could be due to lower population size. A similar study has shown that there is no clear relationship between motile subpopulation structure and fertility was obtained $^{15}$

We evaluated endometrial thickness ranges between 6 to 17 $\mathrm{mm}$. We found that pregnancy rates were maximum when the endometrial thickness was between $9-10 \mathrm{~mm}(\mathrm{p}<0.001)$ though there is an increasing trend to positive pregnancy with endometrial thickness between $7 \mathrm{~mm}-14 \mathrm{~mm}$. These findings are similar to a study where the probability of pregnancy was significantly lower in the group with thin Endometrial Thickness $[\mathrm{EMT} \leq 7 \mathrm{~mm}]^{16}$.

As an ovulation inducing agent, 499 patients were administered with FSH and 97 patients were administered with GONAL F. A $12.42 \%$ success rate was observed among the patients administered with FSH whereas $9.28 \%$ was observed for patients administered with GONAL F. In one study, they found the r-FSH 
group used a lower follicle-stimulating hormone dose and produces more mature oocyte per cycle when compared with the urinary FSH and HMG groups ${ }^{17}$ In another study, FSH was shown to have higher birth rates than Clomephine Citrate and Letrazole, according to a randomized trial which showed that live birth rates after FSH was 32\%, 23\% after CC and 19\% after Letrozole ${ }^{18}$.

\section{LIMITATION}

The sample size was small as the study was based on one centre. We also excluded patients with severe male infertility, severe endometriosis, hypospadias, retrograde ejaculation, bilateral tubal block.

\section{CONCLUSION}

Sperm parameters such as prewash sperm concertration, prewash total motile sperm count and postwash total motile sperm count significantly affected the pregnancy rate after intrauterine insemination. Cycles with less than 10 million postwash total motile sperm are significantly less likely to result in a pregnancy. Similar studies need to be conducted with larger population size for predictive accuracy. The optimal treatment strategy needs to be based on individual patient characteristics such as age, treatment efficacy, side effects such as multiple pregnancy and cost considerations.

\section{RECOMMENDATION}

Further studies should be carried out involving large number of participants in multiple centres.

\section{ACKNOWLEDGEMENT}

The authors would like to acknowledge the Managing Director, Surgiscope Hospital for providing permission and cooperating in carrying out this study.

\section{DISCLOSURE}

All the authors declared no competing interest. 


\section{REFERENCES}

1. Cohlen BJ. Should we continue performing intrauterine inseminations in the year 2004?. Gynecologic and obstetric investigation. 2005;59(1):3-13. Available from: https://www.karger.com/Article/PDF/80492.

2. Cohlen B, Bijkerk A, Van der Poel S, Ombelet W. IUI: review and systematic assessment of the evidence that supports global recommendations. Human reproduction update. 2018;24(3):300-319. Available from: 10.1093/humupd/dmx041.

3. Bensdorp AJ, Tjon-Kon-Fat RI, Bossuyt PM, Koks CA, Oosterhuis GJ, Hoek A, Hompes PG, Broekmans FJ, Verhoeve HR, De Bruin JP, Van Golde R. Prevention of multiple pregnancies in couples with unexplained or mild male subfertility: Randomised controlled trial of in vitro fertilisation with single embryo transfer or in vitro fertilisation in modified natural cycle compared with intrauterine insemination with controlled ovarian hyperstimulation. Bmj. 2015;350. Available from: 10.1136/bmj.g7771.

4. Tjon-Kon-Fat RI, Bensdorp AJ, Bossuyt PM, Koks C, Oosterhuis GJ, Hoek A, Hompes P, Broekmans FJ, Verhoeve HR, De Bruin JP, Van Golde R. Is IVF-served two different ways-more cost-effective than IUI with controlled ovarian hyperstimulation? Human reproduction. 2015;30(10):2331-2339. Available from: 10.1093/humrep/dev193.

5. Rawal N, Drakeley A, Haddad N. Intrauterine insemination practice in the UK. Journal of Obstetrics and Gynaecology. [Online] Informa UK Limited; 2008;28(7): 738-741. Available from: 10.1080/01443610802461789.

6. Jeon YE, Jung JA, Kim HY, Seo SK, Cho S, Choi YS, Lee BS. Predictive factors for pregnancy during the first four intrauterine insemination cycles using gonadotropin. Gynecological Endocrinology. 2013;29(9):834-838. Available from: 10.1016/j.fertnstert.2013.07.469

7. Ombelet W, Dhont N, Thijssen A, Bosmans E, Kruger T. Semen quality and prediction of IUI success in male subfertility: A systematic review. Reproductive biomedicine online. 2014;28(3):300-309. Available from: https://www.sciencedirect.com/science/article/abs/pii/S1472648313005762.

8. Sicchieri F, Silva AB, de Sá Rosa AC. Prognostic factors in intrauterine insemination cycles. JBRA assisted reproduction. 2018;22(1):2. Availablefrom: 10.5935/1518-0557.20180002.

9. Norsina MA. Associated factors affecting the successful pregnancy rate of intrauterine insemination at International Islamic University Malaysia (IIUM) Fertility Centre. Med J Malaysia. 2011;66(3):195. Available from: http://e-mjm.org/2011/v66n3/Intrauterine_Insemination.pdf.

10. Osaikhuwuomwan J, Iribhogbe O, Aziken M, Orhue A. The Effect of Female Age on the Outcome of Intrauterine Insemination Treatment in a Public Hospital-Assisted Reproduction Technology Unit. Nigerian journal of clinical practice. 2018;21(8):988-992. Available from: https://www.ajol.info/index.php/njcp/article/view/175722.

11. Yang S, Peng HY, Li Y, Zhou LY, Yuan L, Ma YM, Wang HC, Li R, Liu P, Qiao J. Intrauterine insemination treatment strategy for women over 35 years old: Based on a large sample multi-center retrospective analysis. Chinese medical journal. 2016;129(23):2873. Available from: 10.1093/oxfordjournals.humrep.a019244.

12. Speyer BE, Abramov B, Saab W, Doshi A, Sarna U, Harper JC, Serhal P. Factors influencing the outcome of Intrauterine Insemination (IUI): Age, clinical variables and significant thresholds. Journal of Obstetrics and Gynaecology. 2013;33(7):697-700. Available from: 10.3109/01443615.2013.810199.

13. Ge ZJ, Schatten H, Zhang CL, Sun QY. Oocyte ageing and epigenetics. Reproduction (Cambridge, England). 2015;149(3):R103. Available from: 10.1530/REP-14-0242.

14. Vichinsartvichai P, Siriphadung S, Traipak K, Promrungrueng P, Manolertthewan C, Ratchanon S. The influence of women age and successfulness of Intrauterine Insemination (IUI) cycles. J Med Assoc Thai. 2015 Sep 1;98(9):833 Available from:https://www.researchgate.net/profile/Patsama_Vichinsartvichai/publication/283126408_The_influence_of_women_age_and_successful ness_of_intrauterine_insemination_IUI_cycles/links/5655e2ef08aeafc2aabeb316/The-influence-of-women-age-and-successfulness-of-intrauterine-insemination-IUI-cycles.pdf.

15. Quintero-Moreno A, Rigau T, Rodr guez-Gil JE. Regression analyses and motile sperm subpopulation structure study as improving tools in boar semen quality analysis. Theriogenology. 2004;61(4):673-690. Available from: 10.1016/S0093-691X(03)00248-6.

16. Kasius A, Smit JG, Torrance HL, Eijkemans MJ, Mol BW, Opmeer BC, Broekmans FJ. Endometrial thickness and pregnancy rates after IVF: A systematic review and meta-analysis. Human reproduction update. 2014;20(4):530-541. Available from: 10.1093/humupd/dmu011.

17. Demirol A, Gurgan T. Comparison of different gonadotrophin preparations in intrauterine insemination cycles for the treatment of unexplained infertility: A prospective, randomized study. Human Reproduction. 2007;22(1):97-100. Available from: 10.1093/humrep/del335.

18. Diamond MP, Legro RS, Coutifaris C, Alvero R, Robinson RD, Casson P, et al. Letrozole, Gonadotropin, or Clomiphene for Unexplained Infertility. New England Journal of Medicine. [Online] Massachusetts Medical Society. 2015;373(13): 1230-1240. Available from: doi:10.1056/nejmoa1414827. 